\title{
Huge Thyroglossal Duct Cyst Mimicking As Goiter In An Adult Man
}

\author{
Iqbal Hussain Udaipurwala, Sana Muhammad Sadiq, Sohail Aslam
}

ABSTRACT:

Thyroglossal duct cyst is the most common congenital cervical mass found mainly in children but only $7 \%$ of them are among adult population. They are mostly asymptomatic and found around the region of hyoid bone. Their size usually varies around 1.5 to $3 \mathrm{cms}$. but cases are reported with unusually larger sized cysts, which may cause pressure symptoms over upper aero-digestive tract. We are reporting a case of unusually huge thyroglossal cyst of size of 6 x $8 \mathrm{cms}$ in a $26-$ year-old man. This cyst was not apparent at time of birth or in early childhood but appeared later on. Initially it was very small but progressively and gradually increased to its present size. On first look, it appeared as thyroid swelling with soft to firm in consistency but on examination it was moving with both deglutition and tongue protrusion. Ultrasonography and CT scan of the neck confirmed the diagnosis of thyroglossal cyst. Thyroid scan showed, thyroid gland in its normal position. Sistrunk's operation was done with a midline vertical incision and the subsequent recovery was uneventful.

Key Words: Thyroglossal duct cyst, congenital neck masses, Sistrunk's operation

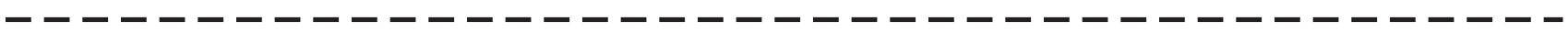

\section{INTRODUCTION:}

Thyroid gland is the first endocrine gland which appears in the 3 rd week of embryonic life near foramen cecum ${ }^{1}$. Initially it remains connected to gut through a narrow stalk called thyroglossal duct, while it descends in the neck and by $10^{\text {th }}$ week of gestational life, the duct obliterates. Sometimes this duct may persist and runs from foramen cecum to thyroid gland's anatomical location in the neck and sometimes a cyst may develop within this duct later in life to appears as a midline cervical mass. Thyroglossal duct cyst is a common and frequent congenitally present midline neck mass in children. Majority of the thyroglossal duct cysts are usually diagnosed till the age of 5 years and only $7 \%$ are found in adult population ${ }^{2}$. It has a slight male preponderance. It is mostly found around the hyoid bone but may be found at any place along the tract of the duct ${ }^{3}$. Most of the thyroglossal cysts are small in size but in literature some cases of unusually large size are reported which may compromise the upper aerodigestive tract. Sistrunk operation is found to be gold standard surgical procedure, while specimen is sent for confirmed histopathological diagnosis.

\section{CASE REPORT:}

A 26-year-old man presented with complaint of a painless

Iqbal Hussain Udaipurwala
Professor \& Head of ENT Department
Bahria University Medical and Dental College, Karachi
Sana Muhammad Sadiq
Assistant Professor, Department of ENT,
Bahria University Medical and Dental College, Karachi
Email: sanaent1112@ gmail.com
Sohail Aslam
Assistant Professor, Department Of ENT,
Bahria University Medical and Dental College, Karachi
Received: 12-08-2019
Accepted: 01-10-2019

lump in front of the neck since 18 years of age, which slowly enlarged in size over last 8 years. Initially it was very small up to the size of an almond but gradually increased and reached up to its present size. It was painless and despite of its large size it was not associated with dyspnoea, stridor or dysphagia. On examination, patient was of average height and built, conscious, well oriented with person, time and place and vitally stable. There was a large sized lump in front of neck, up to $6 \times 8 \mathrm{cms}$. in size, moving with both deglutition and on tongue protrusion (fig. 1). Overlying skin was normal and freely mobile. The consistency was soft to firm with no fluid thrill. Pemberton's sign was negative, and no cervical lymphadenopathy was present. Rest of the clinical examination was also unremarkable.

Ultrasonography of the neck was advised, which revealed the presence of a cystic swelling. Thyroid scan was done which showed normal thyroid gland in its normal position. Thyroid function tests were also within normal limits. C.T scan was also done to find the extent of the lesion which showed presence of a huge thyroglossal duct cyst in the infrahyoid region, with compromise or displacement of airway or food passage (fig 2 and 3). Baseline investigations for general anaesthesia were found within limits and fitness was taken. Sistrunk operation was planned and vertical midline neck incision was used because of better exposure in this big cyst. It was a huge sized cyst, which appeared benign on macroscopic appearance and filled with straw coloured fluid. Surgery and subsequent post-operative recovery were uneventful (fig 4). Biopsy specimen was sent for histopathology which confirmed the diagnosis of thyroglossal cyst.

\section{DISCUSSION:}

Thyroglossal duct cysts are found mostly in $1^{\text {st }}$ decade of life but sometimes in late teen or adult age cases may be reported. $60 \%$ cases appear before 20 years of life while only $7 \%$ cases are detected in adult life ${ }^{4,5}$. In a large study 
Fig 1. Pre-Operative Appearance of the cyst

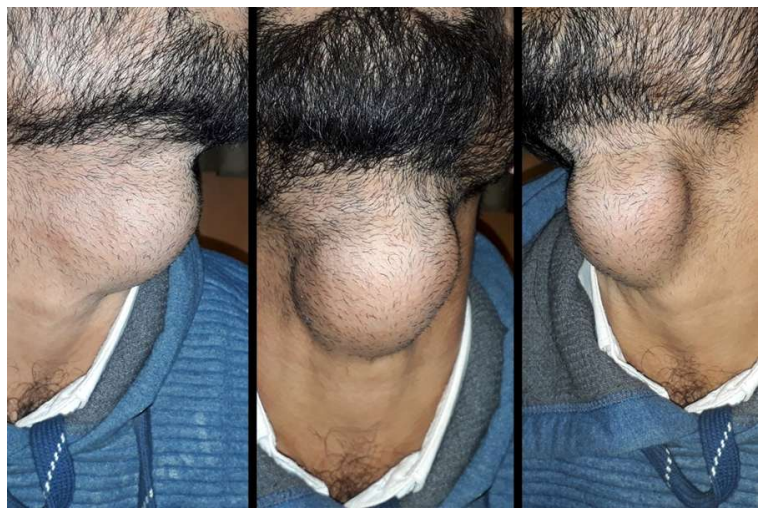

Fig 2 CT scan findings on axial view

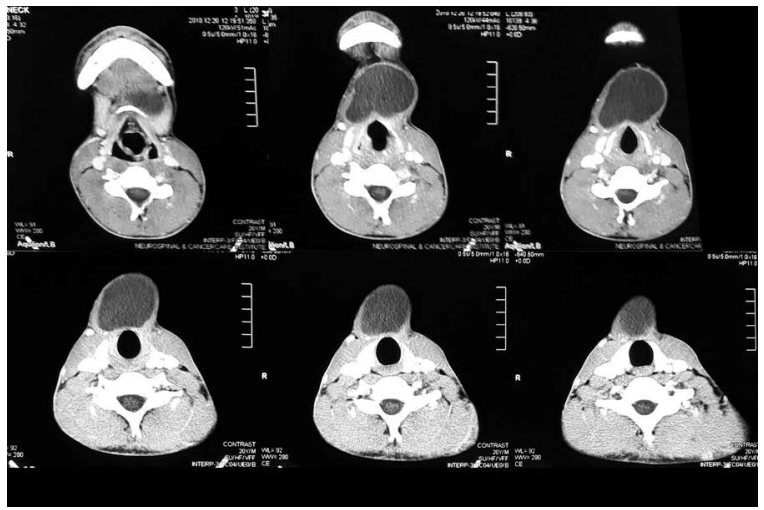

Fig 3. CT scan findings on coronal view

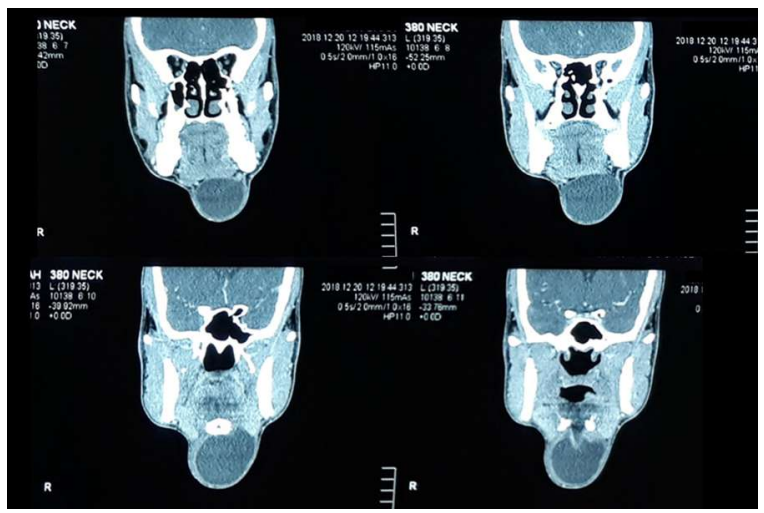

Fig 4. Post-operative appearance after 4 weeks

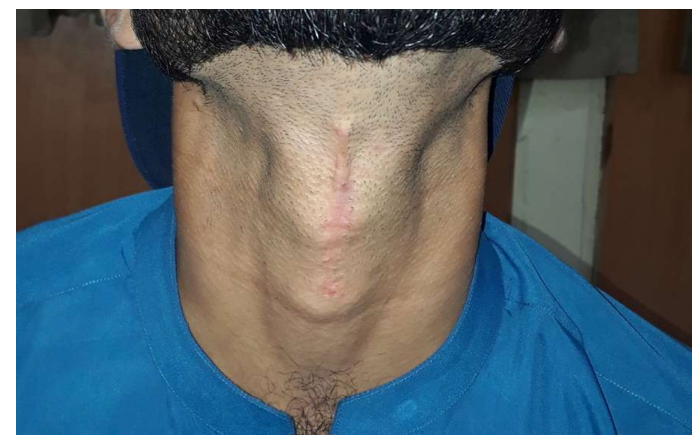

about congenital neck masses in paediatric population, $55 \%$ were diagnosed as thyroglossal duct cysts ${ }^{6}$. It is mostly found in the infrahyoid or sub-hyoid region but may present at any point along the tract of the thyroglossal duct. Atypical presentations also include along floor of the mouth ${ }^{7}$, intralaryngeal ${ }^{8}$, as a thyroid nodule in the lateral neck ${ }^{9}$, as cutaneous extrusion $^{10}$, or in the mediastinum ${ }^{11}$. Mostly these are asymptomatic except producing a cosmetically bad appearance, but larger ones may displace the trachea and /or oesophagus and thus pressure symptoms may appear like dyspnoea, stridor or dysphagia. Sometimes due to repeated infections, cyst may rupture and presents as fistulous tract or discharging sinus. In our case, the cyst appeared in the adult man after the age of 18 years. Though it was a huge cyst, there was no compression symptom and on inspection it appeared as a goitre. The patient in this case was also male as thyroglossal cyst is more common in males.

Ultrasound is usually the first investigation, which confirms the presence of the cyst. In our case also ultrasonography showed a huge cyst. Fine needle aspiration cytology reveals the nature of cells within the cyst. As it was a clear case of fluid filled thyroglossal cyst so fine needle aspiration cytology was not done in this case. In large cysts, C.T scan is advised to know the extent of the lesion. We also performed CT scan to see the extent of the cyst which showed a huge fluid filled cyst in the midline extending from the hyoid bone till upper tracheal rings. Thyroid function tests and thyroid scan are needed to rule out a normally functioning thyroid tissue in the body. In our case both were within normal limits.

Sistrunk operation is found to be gold standard treatment for such cases, in which TGD cyst is removed along with a part of central region of hyoid bone and a core of muscles around base of the tongue to avoid recurrence. This procedure carries $2.6-5 \%$ recurrence rate, depends upon the location of the cyst, surgeon's expertise, pre-operative infections etc. We also performed Sistrunk's operation. Ideally horizontal neck incision is used for this surgery, but we preferred midline vertical incision for better exposure as this was a huge cyst. There was no recurrence of the cyst in followup period of about 6 months. Use of operating microscope has been advocated by a recent study to identify the thyroglossal duct remnant better and to reduce chances of recurrence ${ }^{12}$.

Thyroglossal cysts are mostly benign, but few cases are reported which harbour carcinoma in around $1 \%$ of the cases and out of which $75-80 \%$ cases are found to be papillary carcinoma. In our case histopathology of specimen was done after surgery which confirmed its benign and cystic nature with no evidence of malignancy. The lining epithelium of the cyst is mostly stratified squamous or sometimes pseudostratified ciliated columnar epithelium and rarely cyst may be devoid of any epithelium. In this case, the lining epithelium was stratified squamous. 


\section{CONCLUSION:}

Thyroglossal duct cysts are congenitally present benign cervical masses, which mostly produce bad cosmetic appearance and no other symptoms. We are presenting a case of huge thyroglossal cyst in an adult man which was mimicking as a goitre because of its size.

\section{REFERENCES:}

1. Carter Y, Yeutter N, Mazeh H. Thyroglossal duct remnant carcinoma: beyond the Sistrunk procedure. Surg Oncol. 2014; 23(3): 161-6.

2. Kurt A, Ortug C, Aydar Y, Ortug G. An incidence study on thyroglossal duct cysts in adults. Saudi Med J. 2007; 28: 593-7

3. Al-Thani H, El-Menyar A, Al- Sulaiti M, El-Mabrok J, Hajaji K, Elgohary H, Asim M, Taha I, Tabeb A. Presentation, Management, and Outcome of Thyroglossal Duct Cysts in Adult and Pediatric Populations: A 14-Year Single Center Experience. Oman Medical Journal, 2016; 31(4): 276-83.

4. Lin ST, Tseng FY, Hsu CJ, Yeh TH, Chen YS. Thyroglossal duct cyst: a comparison between children and adults. Am J Otolaryngol., 2008; 29(2): 83-87.

5. Dedivitis RA, Camargo DL, Peixoto GL, Weissman L, Guimarães AV. Thyroglossal duct: a review of 55 cases. J Am Coll Surg, 2002; 194(3): 274-277.
6. Hsieh YY, Hsueh S, Hsueh C, Lin JN, Luo CC, Lai JY, Huang CS. Pathological analysis of congenital cervical cysts in children: 20 years of experience at Chang Gung Memorial Hospital. Chang Gung Med J, 2003; 26(2): 107-113.

7. Nakayama S, Kimachi K, Nakayama K, Ozeki S. Thyroglossal duct cyst occurring in the floor of the mouth: report of 2 cases . J Oral Maxillofac Surg, 2009; 67: 2690-3.

8. Nicollas R, Mimouni O, Roman S, Triglia JM. Intralaryngeal manifestation of thyroglossal duct cyst. Otolaryngol Head Neck Surg, 2007; 137: 360-1.

9. Shifrin A, Vernick J . A thyroglossal duct cyst presenting as a thyroid nodule in the lateral neck. Thyroid, 2008; 18: 263 5 .

10. Nomdedéu-Guinot J, Martínez-Ramos D, Gibert-Gerez J, et al . Cutaneous extrusion as an atypical manifestation of a thyroglossal duct cyst . Cir Esp, 2008; 84: 173-4.

11. Chon SH, Shinn SH, Lee CB, et al . Thyroglossal duct cyst within the mediastinum: an extremely unusual location. J Thorac Cardiovasc Surg, 2007; 133: 1671-2.

12. Akram A, Tariq M, Shahid RA. Thyroglossal duct cyst excision under magnification - How I do it? Pak J Med Health Sci., 2018; 12(2): 855-6. 